\title{
Holistic Design of HTHP Pipeline: PETRONAS' Experience
}

\author{
Hayati Hayati ${ }^{1, *}$, Azam Syah Jaafar ${ }^{1}$, Nur Atika Abdul Latif ${ }^{1}$ and Mohd Faisal Aziz ${ }^{1}$ \\ ${ }^{1}$ PETRONAS, Project Delivery \& Technology (PD\&T), Group Technical Solutions (GTS), Infra/ \\ Pipeline, 50050 Kuala Lumpur, Malaysia
}

\begin{abstract}
When the oil and gas price was declining rapidly in 2016, it is prudent for global oil operator to identify opportunity to reduce the development cost. This is where all form of cost optimisation and holistic design approach have to be conducted, especially when dealing with High Pressure and High Temperature (HPHT) pipeline which normally requires higher CAPEX. Referring to a field case example from one of PETRONAS's HPHT pipeline project in Malaysia waters, initial analysis had identified that a 24-inch subsea FWS HPHT pipeline with $40 \mathrm{~mm}$ concrete coating thickness (for its on-bottom stability requirement), requires three numbers of 'buckle trigger's in order to manage the pipeline lateral buckling issues. Hence, a holistic design approach had been conducted to re-evaluate such requirement, commenced with detail assessment to look for all possible opportunities to reduce the pipeline temperature, one of it is to have a greater heat transfer from the pipeline. This exercise had landed into detail assessment on the pipeline on-bottom stability requirement which resulted in indication that the 24-inch FWS pipeline, that have a thicker wall thickness at the upstream portion, would be self-stabled - no requirement for concrete weight coating. Thus, benefitting from the results, further detail analysis had been conducted to assess the overall heat transfer from the pipeline as well as the impact towards the pipeline lateral buckling design, which lead to elimination of lateral buckling mitigation requirement. Unfortunately, further analysis had shown that in the absent of concrete weight coating, the pipeline unconcrete weight coated section i.e. hot end area and the field joints, would have rapid condensation and exposed to the intolerable top of line corrosion risk. Also, based on past experience with local installation contractor, there will be possibility of installation issue for the un-concrete coated pipeline with the tapered bracelet anode. Following that, thorough analysis had been performed and successfully mitigated the issue by applying field joint coating material with $\mathrm{U}$-Value of $52 \mathrm{~W} / \mathrm{m} 2 \mathrm{~K}$ to the 3LPP-Coated linepipe. As for the subsea flange connection, it is covered with thermal insulation, whereas the anode at the un-concrete coated section utilized anode sled mechanism. This holistic design approach had successfully reduced the project cost in line with PETRONAS' aspiration i.e. low cost development project; and most importantly the 'body of knowledge' i.e. experiences, lessons learnt and good practices are captured in PETRONAS Technical Standard for future replication
\end{abstract}

\footnotetext{
* Corresponding author: hayati.h@petronas.com
} 


\section{Introduction}

During the Front End Engineering Design (FEED) in 2014, it was decided that a 24-inch pipeline is required for a field development to deliver $250 \mathrm{MMscf} / \mathrm{d}$ full well stream gas to the nearest processing facility located $13.7 \mathrm{~km}$ away from the proposed wellhead platform location.

The wellhead platform was designed with minimum facility with no pressure relief system and cooling facility to protect the pipeline from being exposed to flowing tubing head pressure and temperature. For these reasons the pipeline was designed fully rated to meet the maximum flowing tubing head pressure of 149.16barg and flowing tubing head temperature of $110^{\circ} \mathrm{C}$. This design envelop is considered high in Malaysia water and based on past project, high temperature high pressure engineering design is required for this project.

In line with the revised pipeline engineering design approach, the FEED and detailed design scope included screening for lateral buckling using analytical approach followed by finite element analysis and lateral buckling design when the result indicated that the maximum compressive force is closed to or exceeded the pipeline critical buckling force.

\section{FEED: defining the challenge}

The lateral buckling screening was performed interactively with the following pipeline design activities:

1) The wall thickness design for pressure containment, hydrostatic collapse, propagation buckling and local buckling which arrived with various minimum required wall thicknesses ranging from $16.46 \mathrm{~mm}$ up to $27.71 \mathrm{~mm}$ depending on the water depth and pipeline/section. After considering strain capacity requirement $(0.51 \%)$ for lateral buckling design, the proposed wall thickness are $28.58 \mathrm{~mm}$ and $20.62 \mathrm{~mm}$ for KP0.0 to KP4.0 (including riser section) and KP4.0 to KP14.0 respectively. The design corrosion allowance for the pipeline is $7 \mathrm{~mm}$ for thicker pipe and $3 \mathrm{~mm}$ for the remaining section.

2) The on-bottom stability analysis was performed using with omni-directional environmental data for conservative purpose. With thicker wall thickness of $28.58 \mathrm{~mm}$, the required concrete coating is $5 \mathrm{~mm}$ for KP 0.0 to KP 4.0, while for the thinner wall thickness $(20.62 \mathrm{~mm})$ section, KP 4.0 to KP 13.7 , the required concrete coating is $25 \mathrm{~mm}$. Considering both KP range's minimum concrete thickness requirement and suited with optimum sacrificial anode (SA) bracelet thickness, the selected concrete coating thickness was $40 \mathrm{~mm}$.

3) Based on the design temperature, 3 layer polypropylene was proposed as the pipeline external corrosion coating.

The above pipeline parameters were incorporated in the steady state hydraulic analysis and generated pipeline temperature profile along the $13.7 \mathrm{~km}$ length pipeline as shown in Fig. 1. 


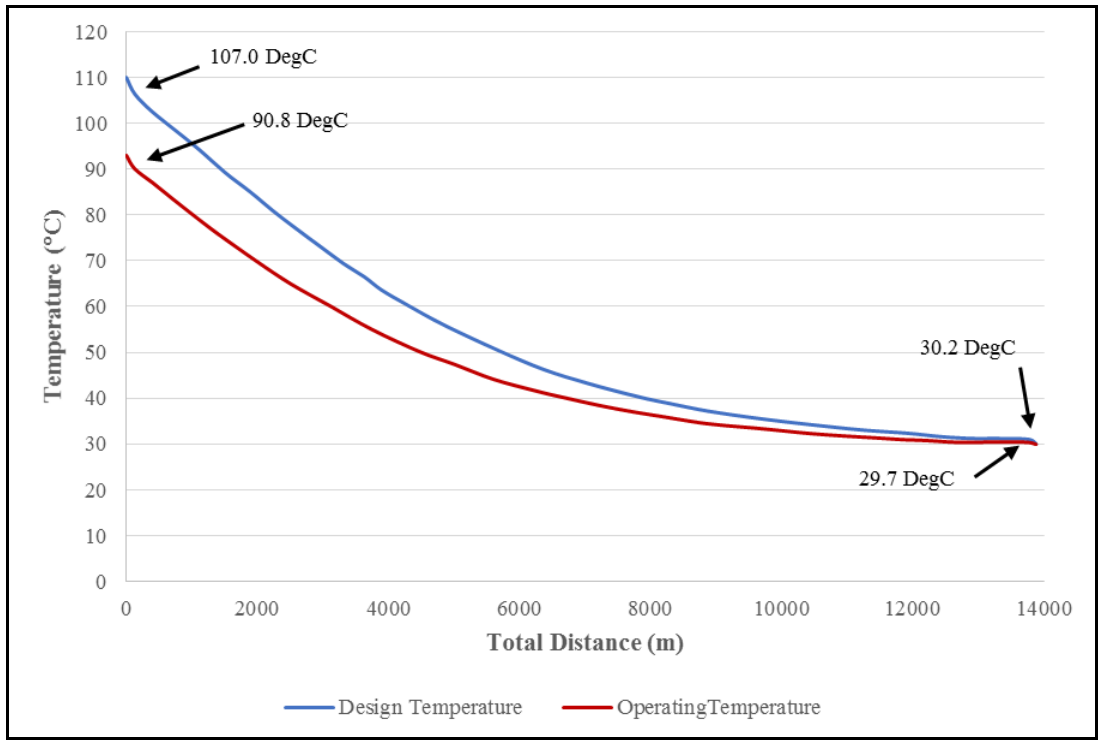

Fig. 1. Pipeline Temperature Profile for Design and Maximum Operating Temperature Cases

\subsection{Pipe-soil interaction}

Pipe-soil interaction is important parameter for HTHP pipeline design. Detailed soil investigation was performed using CPT tools to obtain more accurate soil information for the predominantly clayey soil type. Lower, Mean and Upper Bound soil undrained shear strength curves derived from the data (See Figure. 2) were used in the analysis in the form of Lower Bound, Best Estimate, Upper Bound axial and lateral soil frictions.

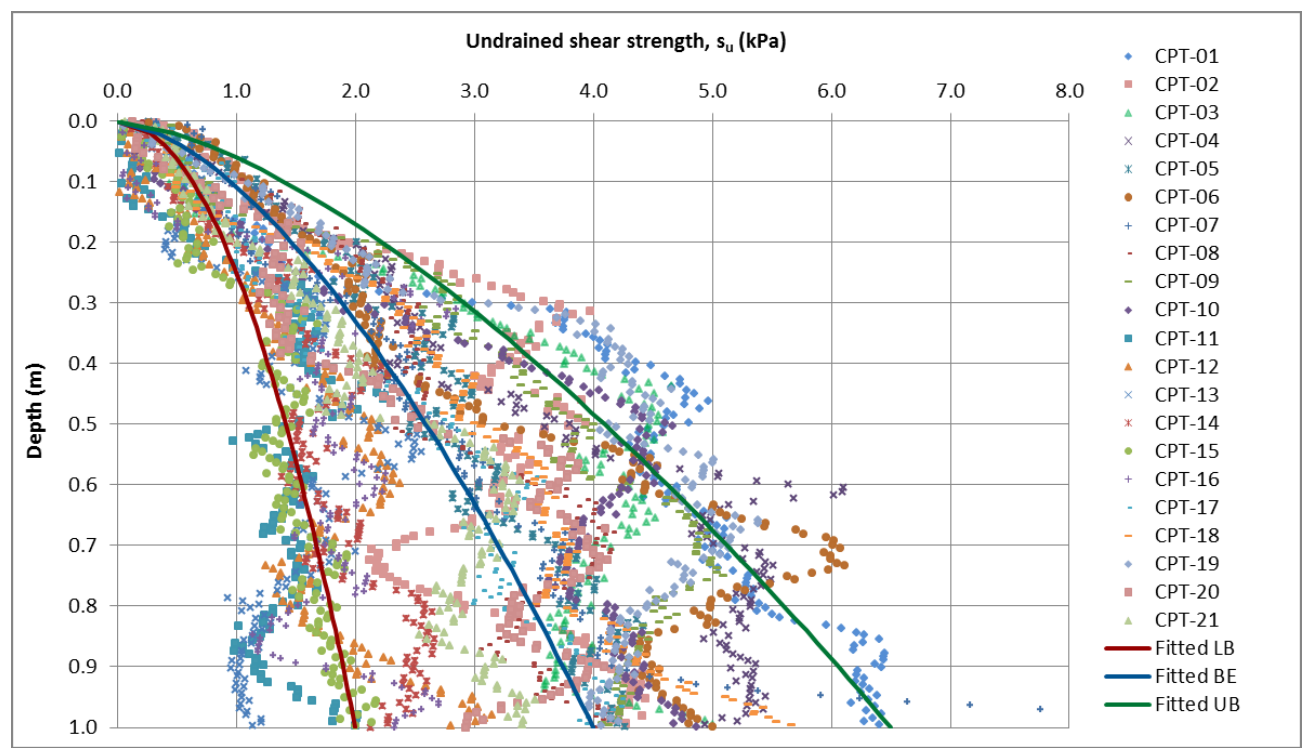

Fig. 2. Lower, Mean and Upper Bound Soil Undrained Shear Strength based on Site Investigation 


\subsection{Analytical lateral buckling susceptibility screening}

The analytical lateral buckling susceptibility screening were performed for various pressure and temperature combinations to assess the likeliness for the buckling to happen. The results presented in Fig. 3 to Fig. 6 shown that the effective axial force cross the critical buckling force around 3 kilometres from the hot end even during normal maximum operating conditions. This indicates that lateral buckling is likely to occur if not mitigated assuming that the pipeline is laid straight on a flat seabed.

In actual fact the seabed would be uneven and lateral out-of- straightness would occur during installation even if the proposed pipeline route is straight. As shown in Fig. 7, the critical buckling force reduce significantly as the imperfection increases and hence higher risk for lateral buckling as indicated in Fig. 8.

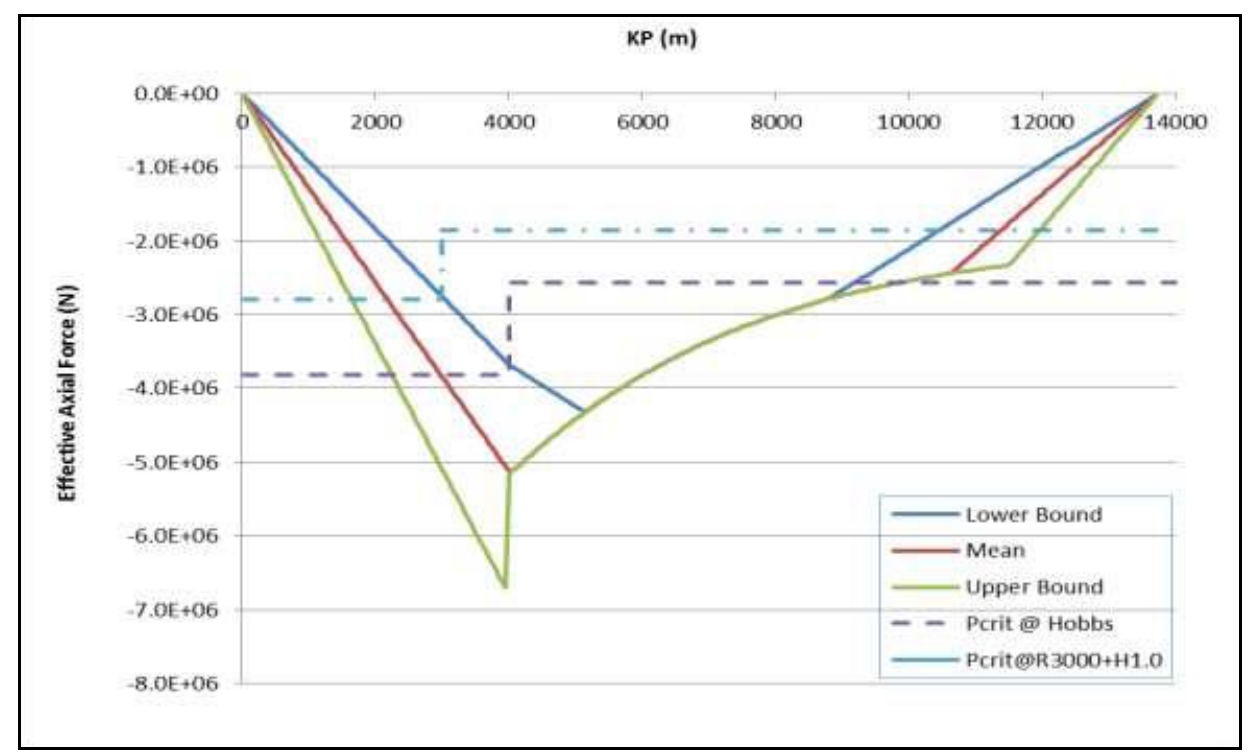

Fig. 3. Unmitigated Effective Axial Force based on Design Temperature and Design Pressure 


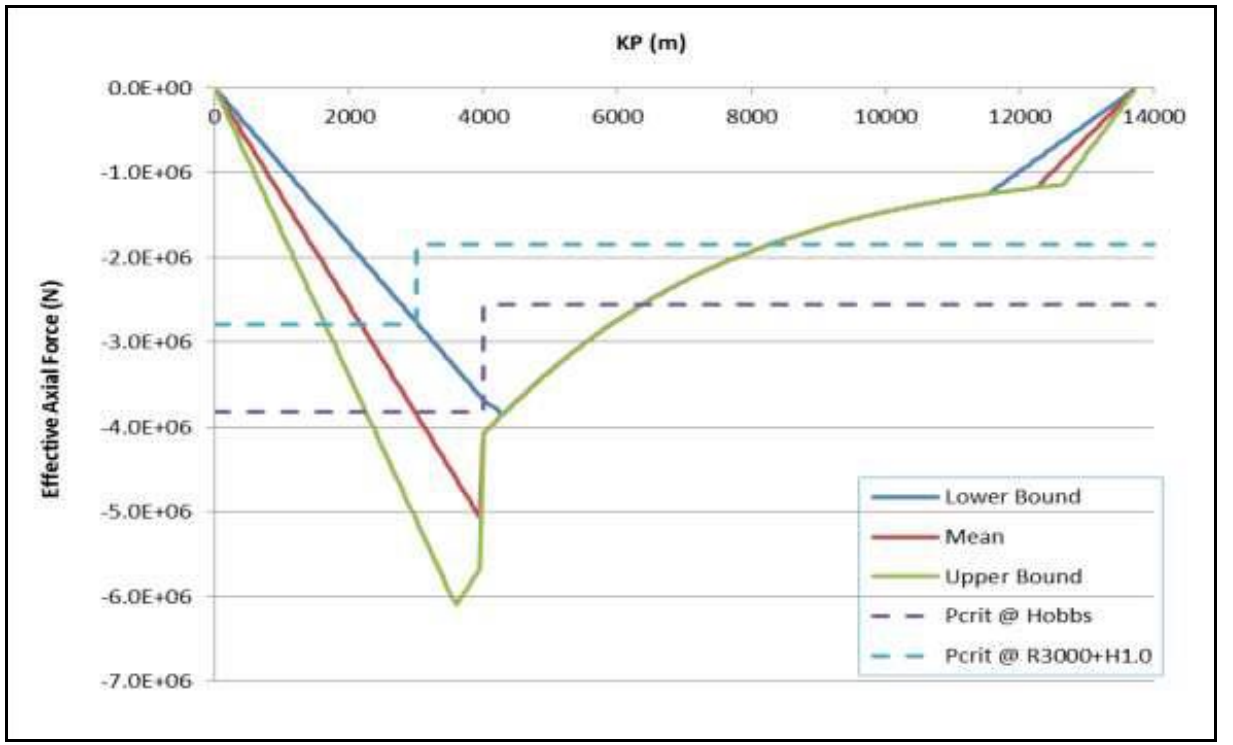

Fig. 4. Unmitigated Effective Axial Force based on Design Temperature and Maximum Operating Pressure

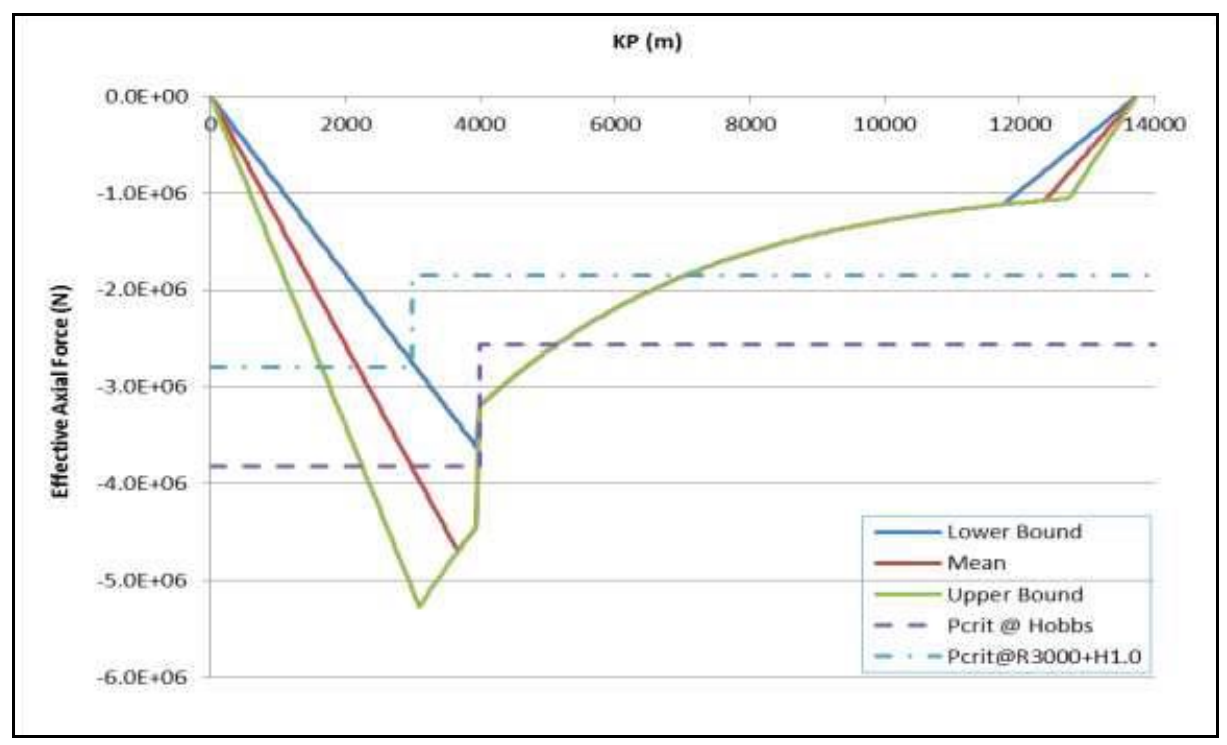

Fig. 5. Unmitigated Effective Axial Force based on Maximum Operating Temperature and Maximum Operating Pressure 


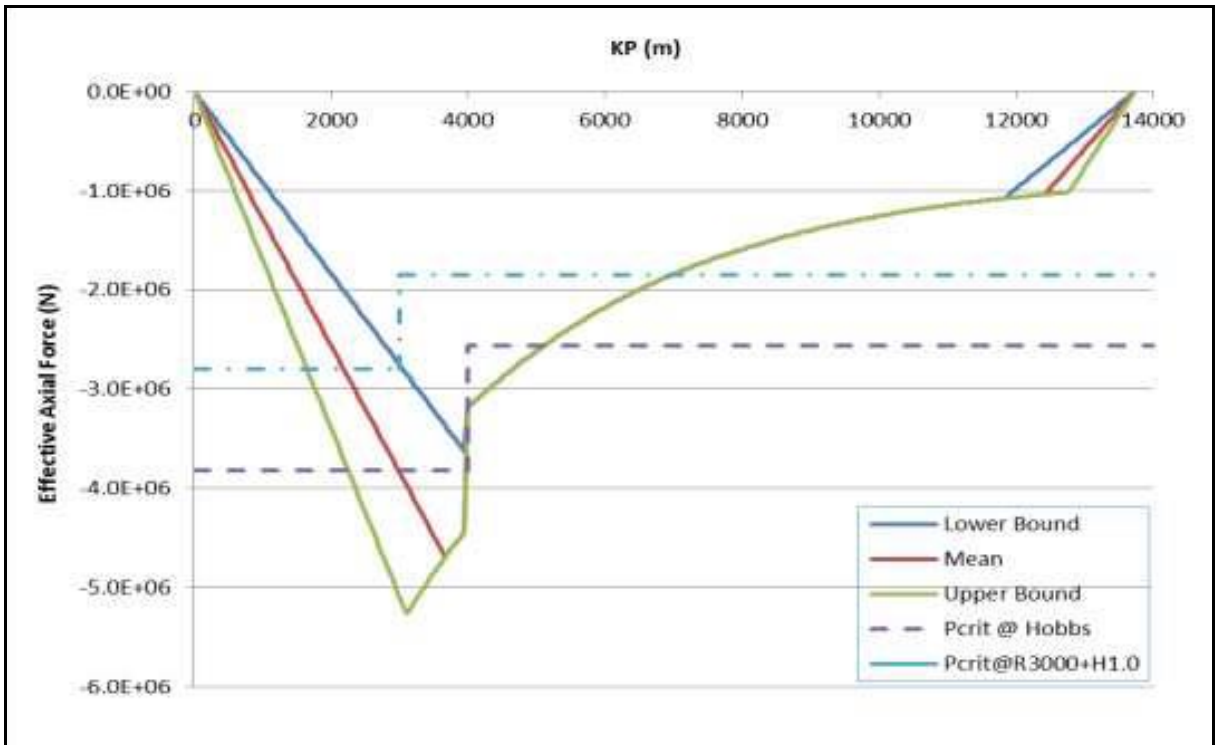

Fig. 6. Unmitigated Effective Axial Force based on Maximum Operating Temperature and Associated Pressure

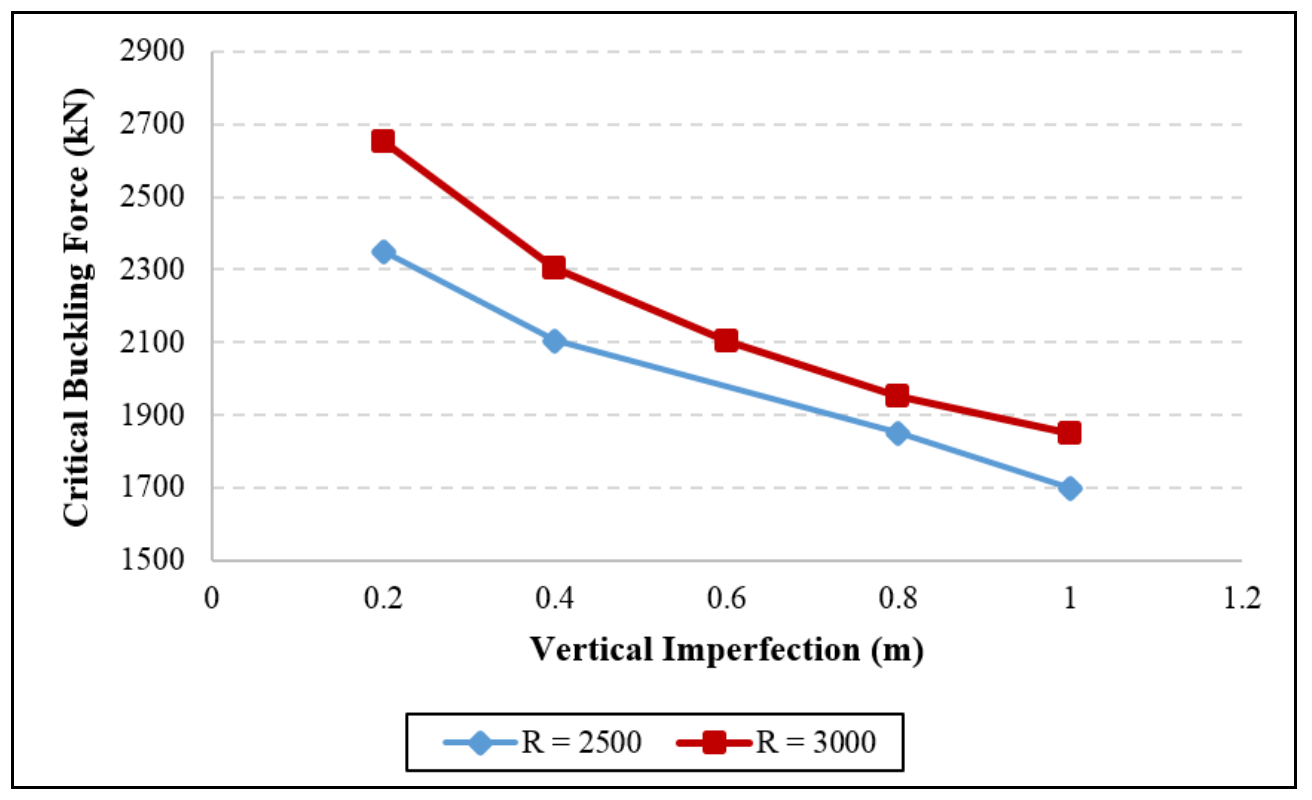

Fig. 7. Critical Buckling Force due to horizontal and Vertical out of Straightness 


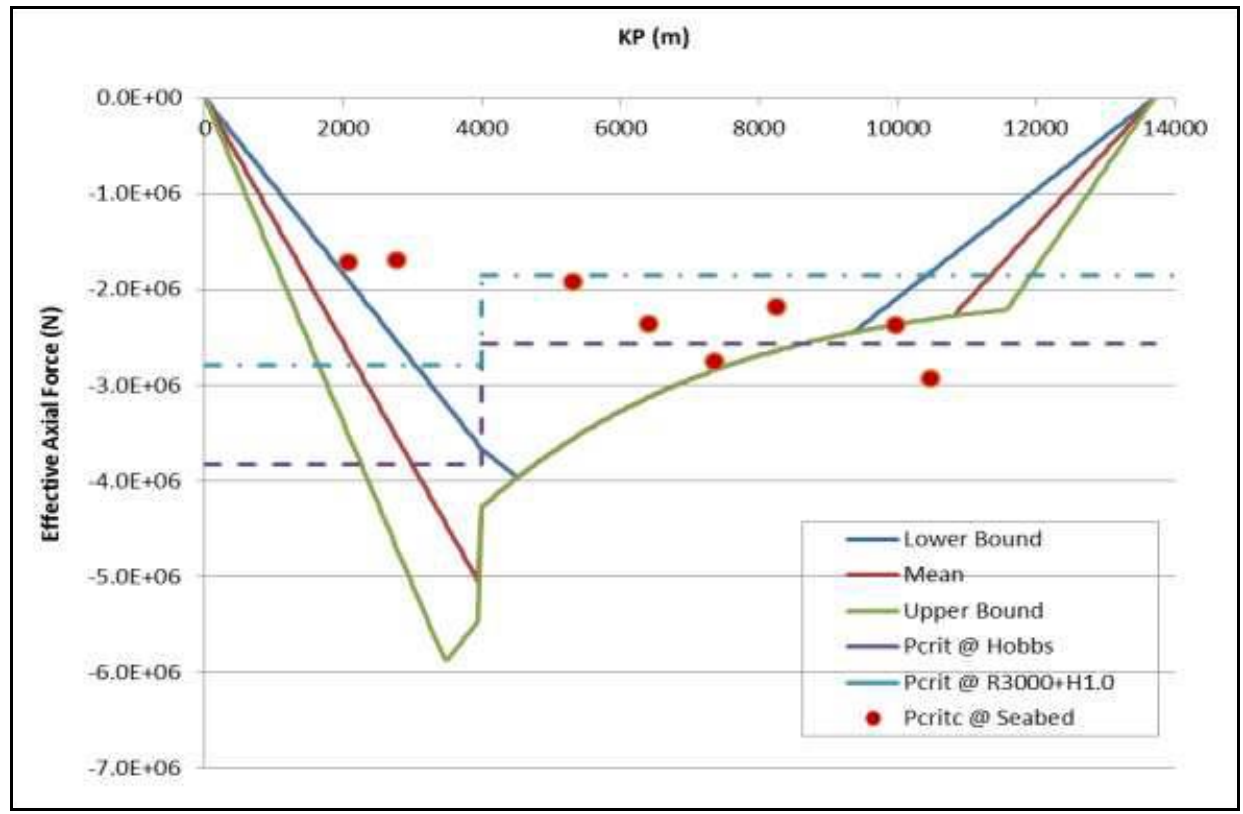

Fig. 8. Lateral Buckling Prone Region

\subsection{D Full model finite element analysis}

The lateral buckling risk was further assessed using three dimensional finite element model covering the whole pipeline length resting on the seabed profile along the proposed route (as seen in Fig. 9 below) to qualify the effect of as installed conditions with no mitigation considered in the model.

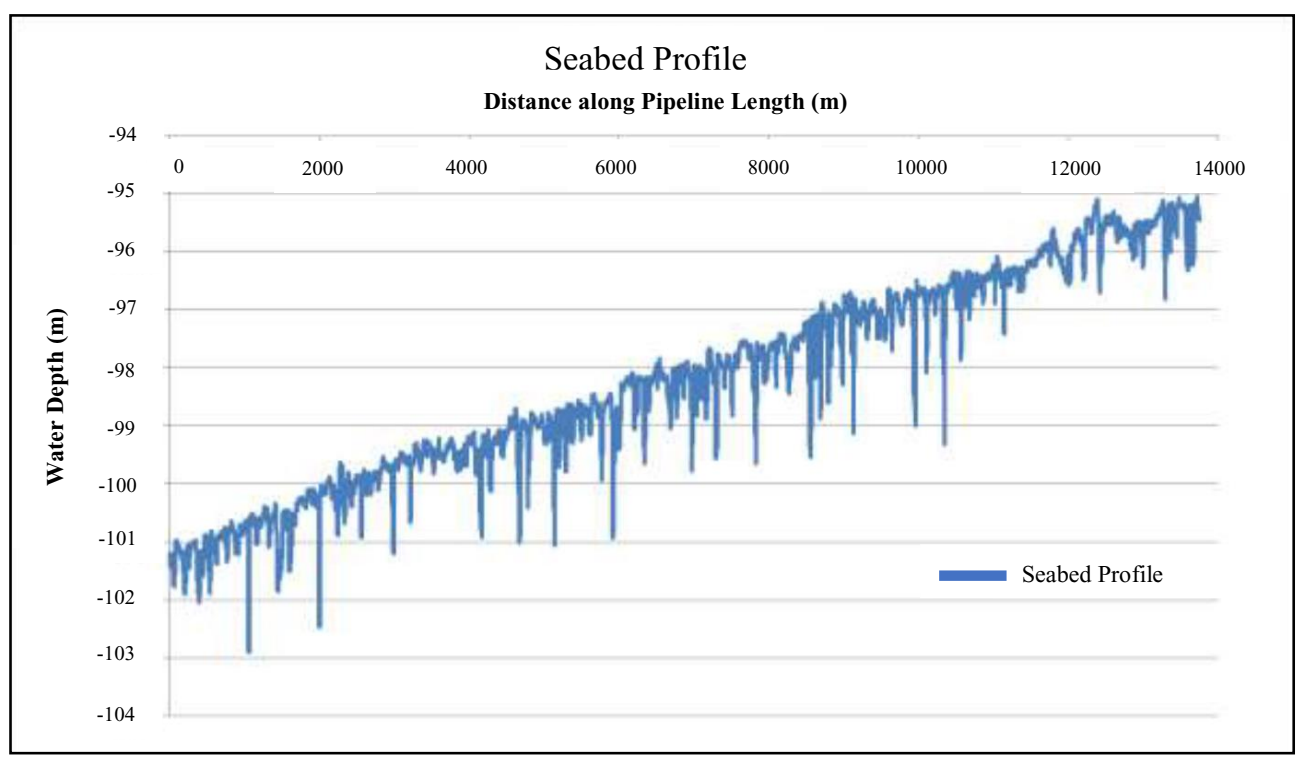

Fig. 9. Seabed Profile along the Proposed Route 
The results of the Von Mises stress, effective axial force, axial mechanical strain, lateral displacement and vertical displacement are reported in Fig. 10, 11, 12, 13 and 14. The three peaks and dips in Fig. 13 indicate possible rogue buckles location while the $1 \mathrm{~m}$ high peak in Fig. 14 indicate upheaval buckling possible location.

The maximum axial compressive of $-0.582 \%$ shown in Fig. 12 exceeds the strain capacity of the pipe (allowable strain limit) of $0.51 \%$. The post buckling axial force in Fig. 11 are generally above the Hobbs critical buckling line. However the bending moments at the three buckles fail LCC local buckling check. Hence mitigation measure is necessary to control the buckle.

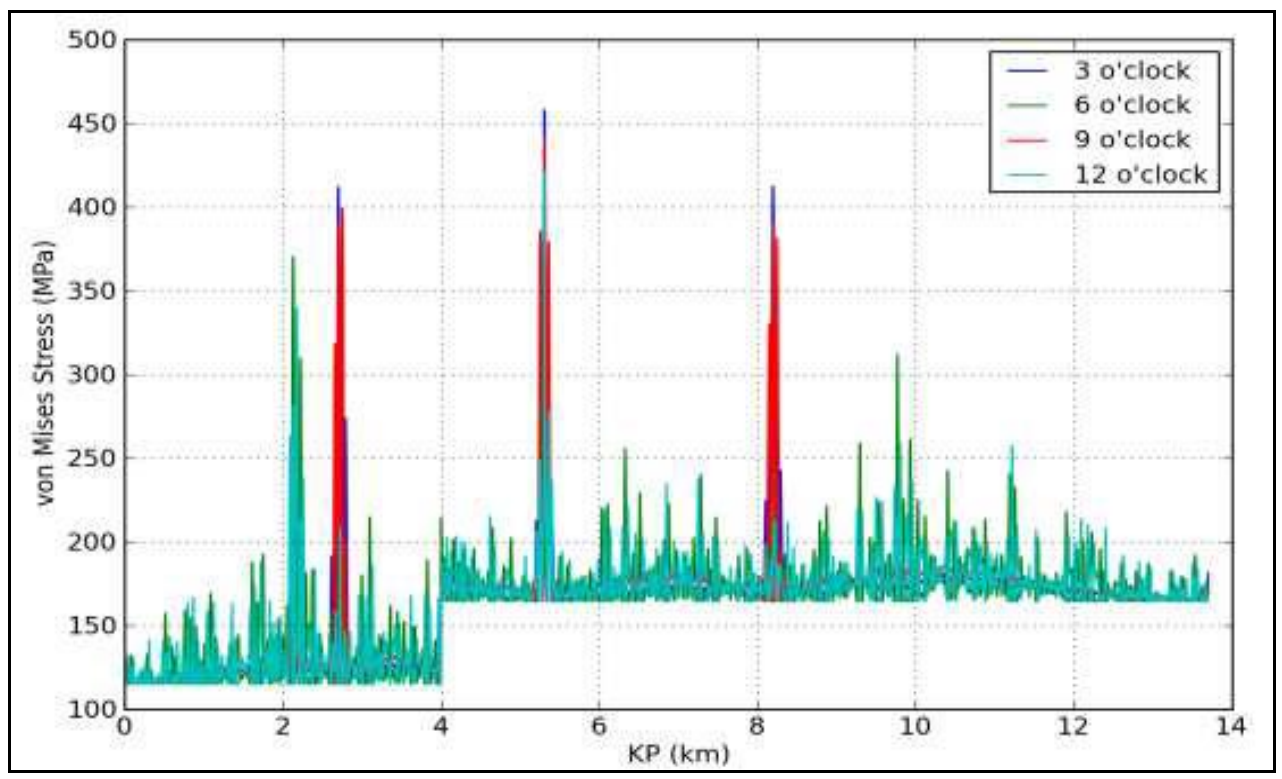

Fig. 10. Von Mises Stress the Pipeline Length

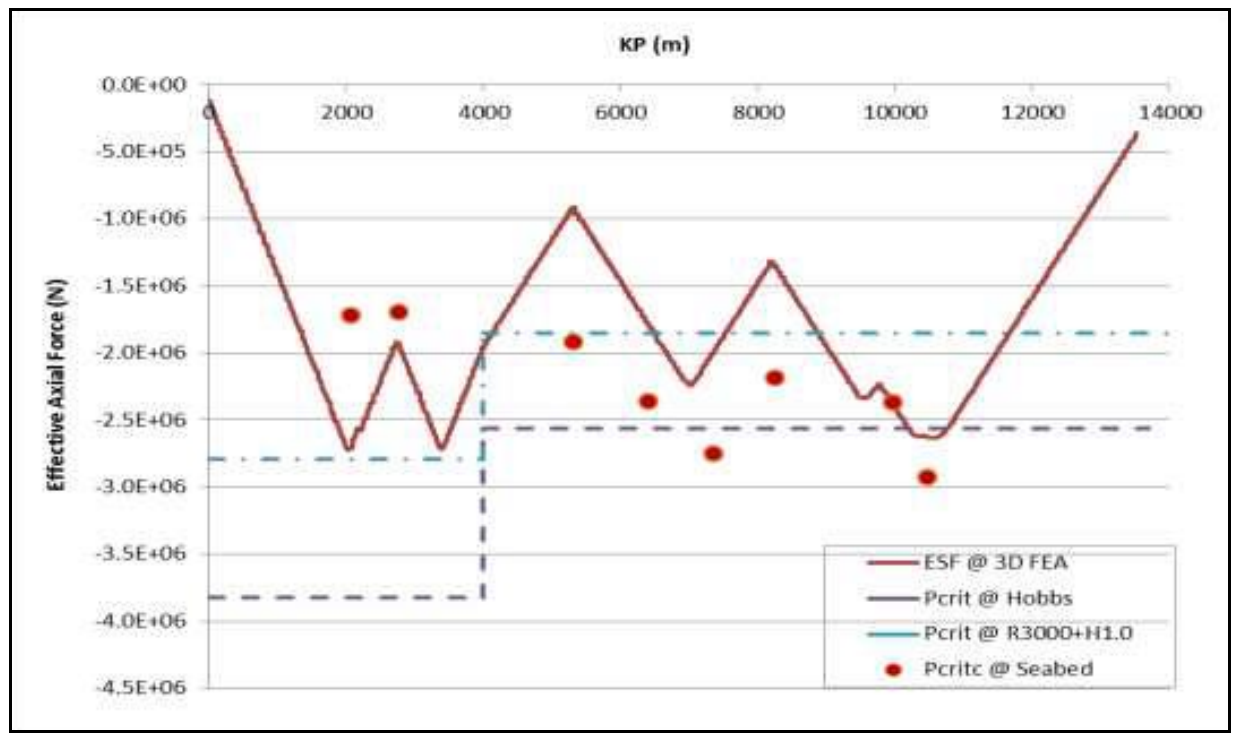

Fig. 11. Effective Axial Force along the Pipeline Length 


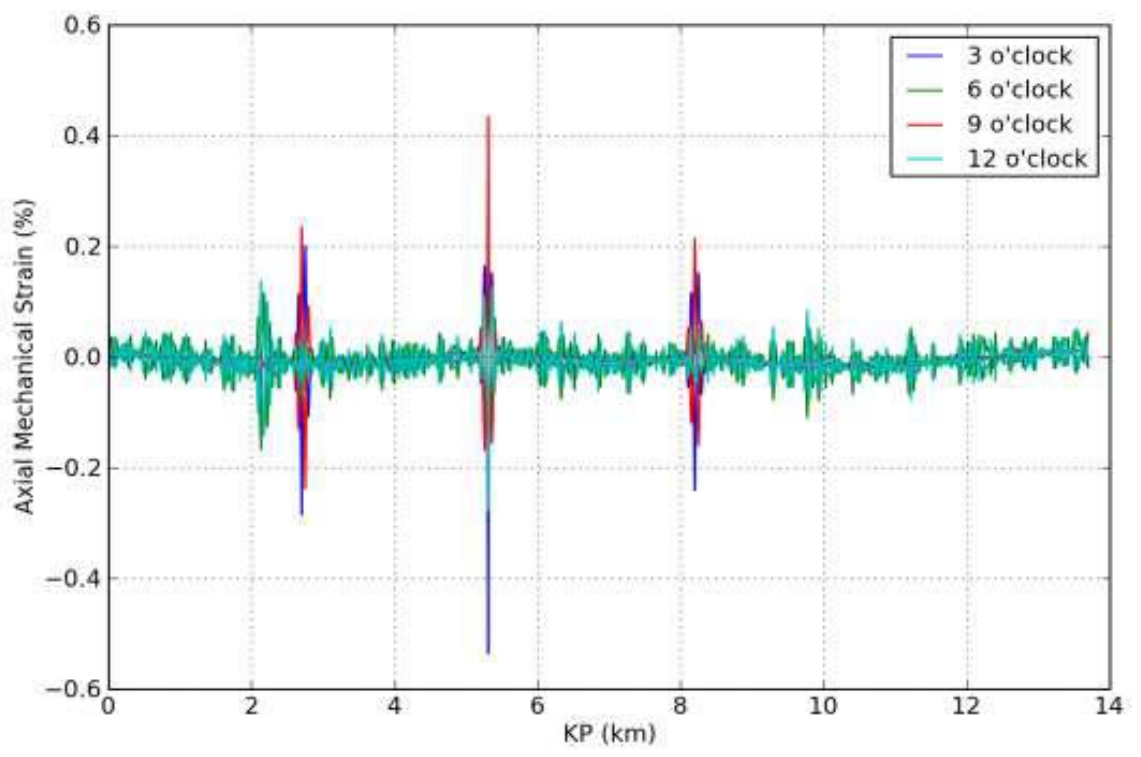

Fig. 12. Axial Mechanical Strain along the Pipeline Length

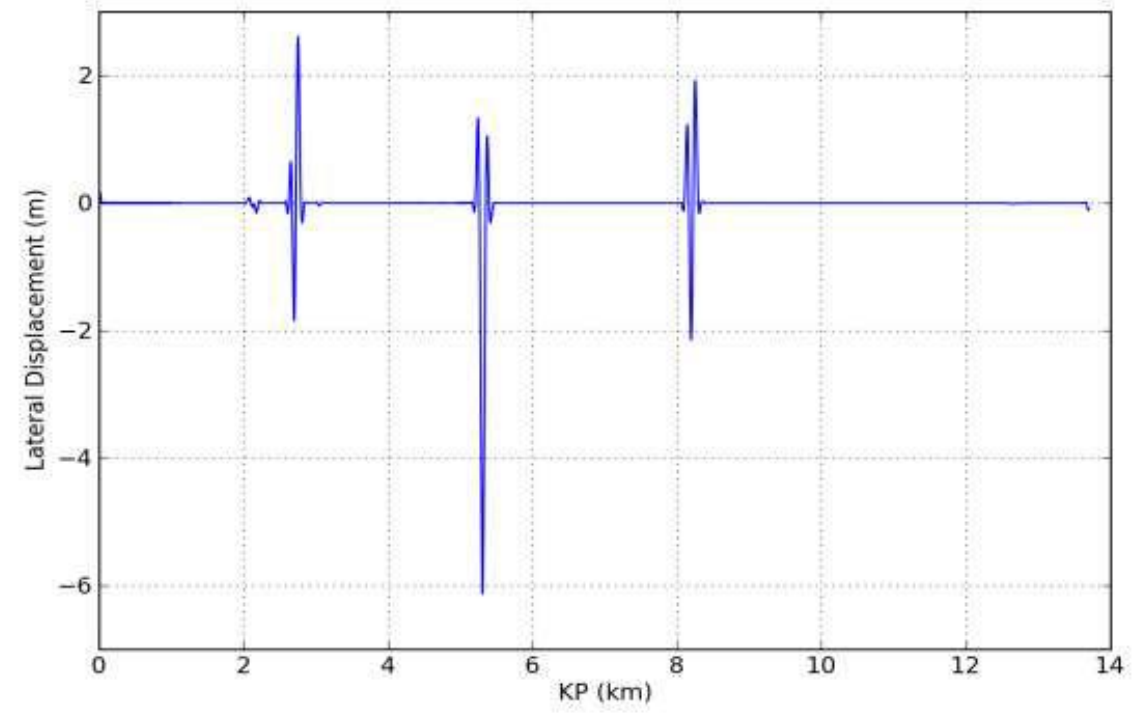

Fig. 13. Lateral Displacement along the Pipeline 


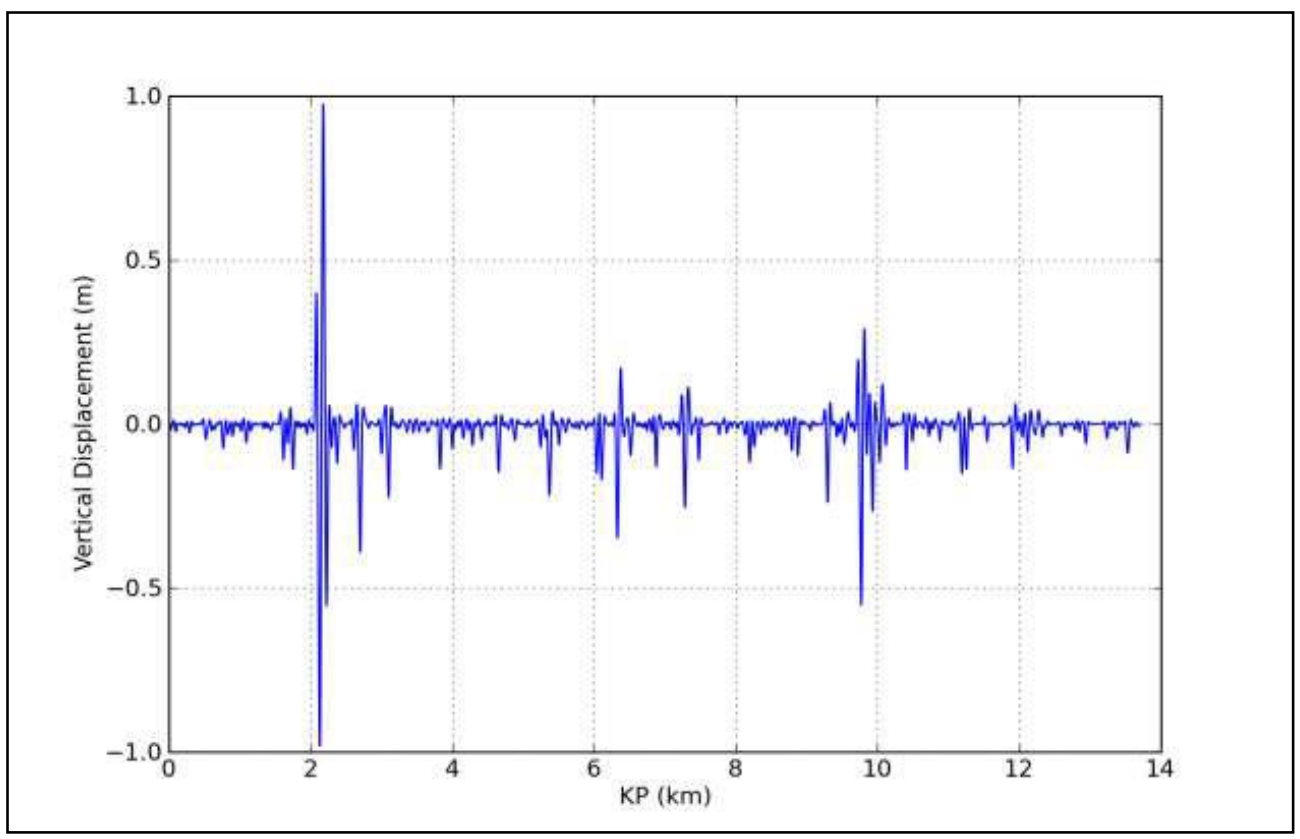

Fig. 14. Vertical Displacement along the Pipeline

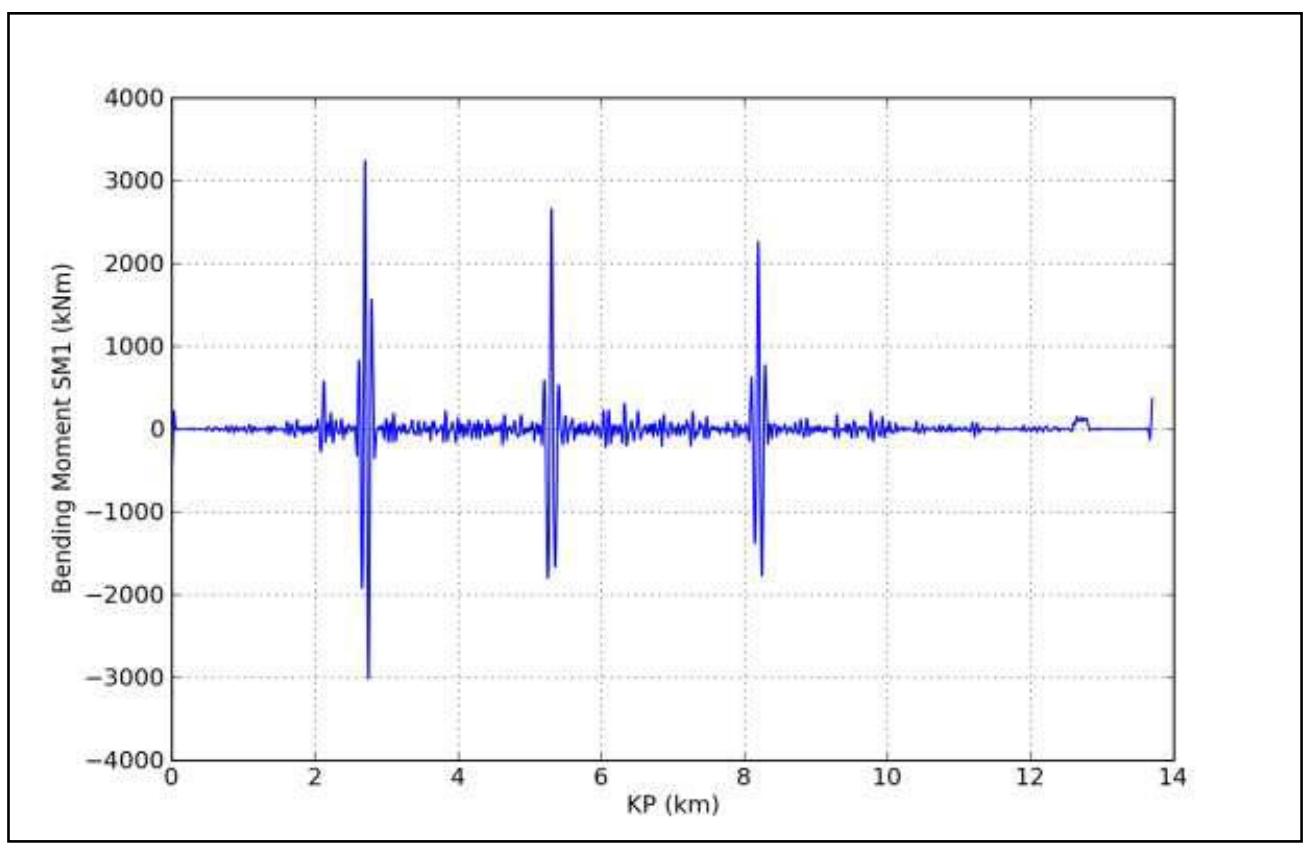

Fig. 15. Bending Moment along Pipeline Length

\subsection{Lateral buckling design}

Buckle mitigation method using Zero-Radius Bend (ZRB) has been proven effective and reliable approach for shallow water pipeline in the region. This approach is adopted for the 
pipeline by having 3 buckle triggers to be installed at KP 3.37, KP 5.72 and KP 8.03 with 9 degrees turning angle and $0.4 \mathrm{~m}$ vertical displacement.

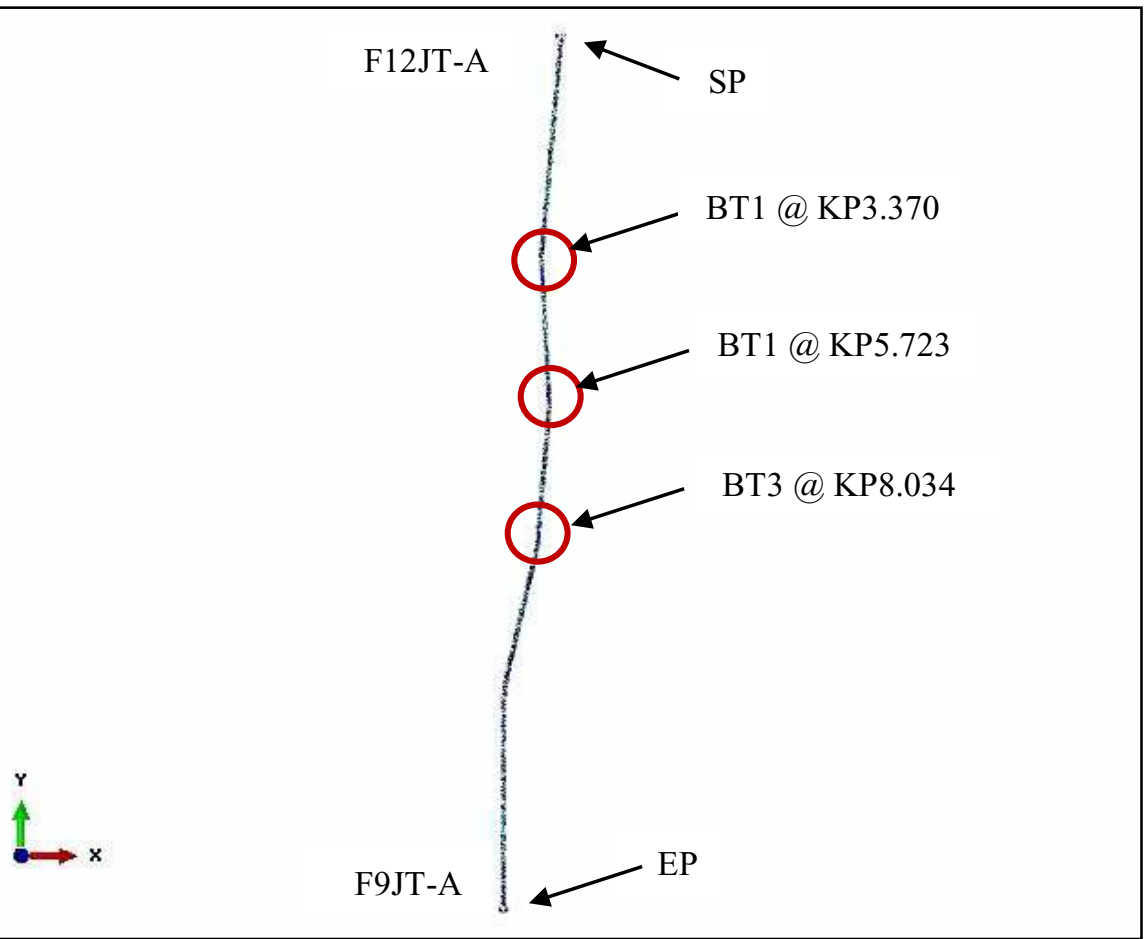

Fig. 16. Buckle Triggers along the Pipeline Length

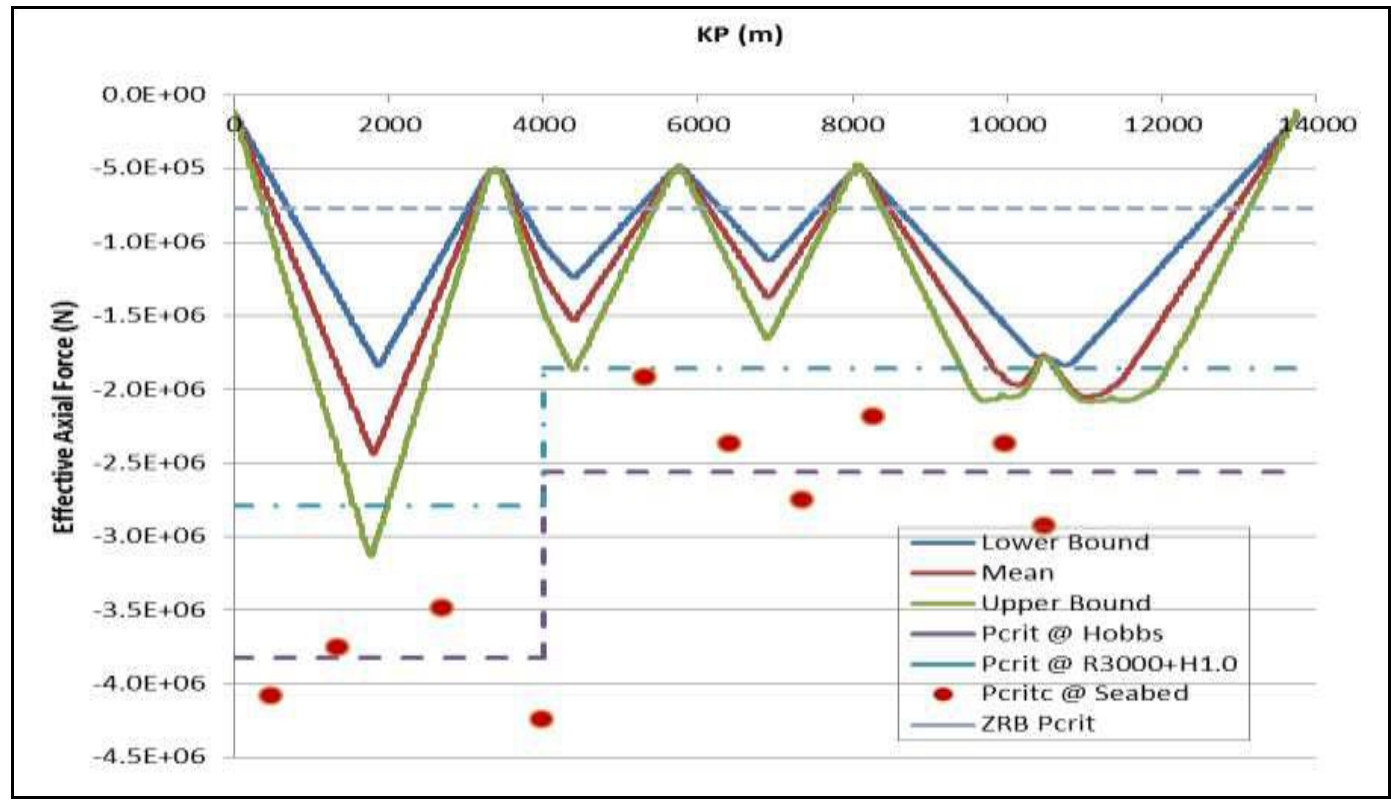

Fig. 17. Effective Axial Force along the Pipeline Length 


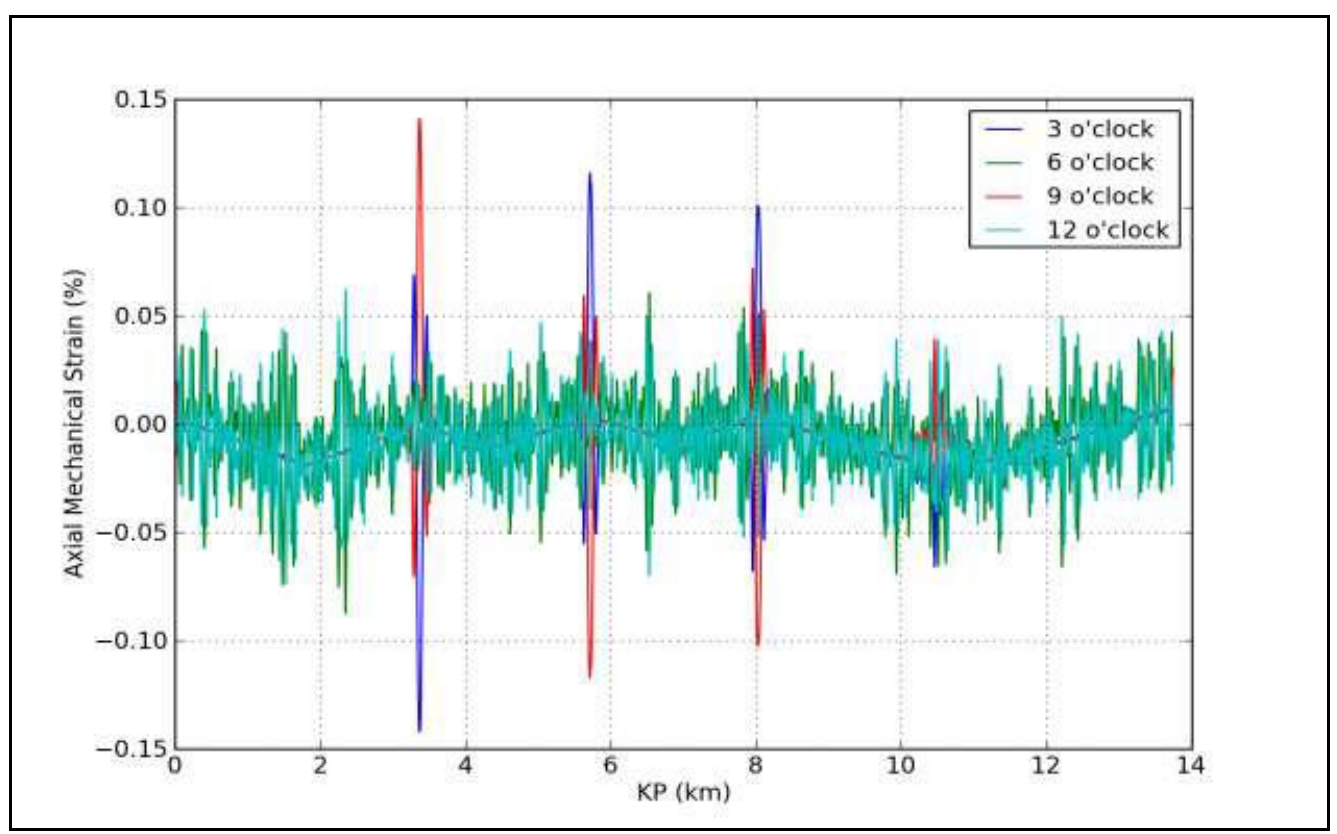

Fig. 18. Bending Moment along Pipeline Length

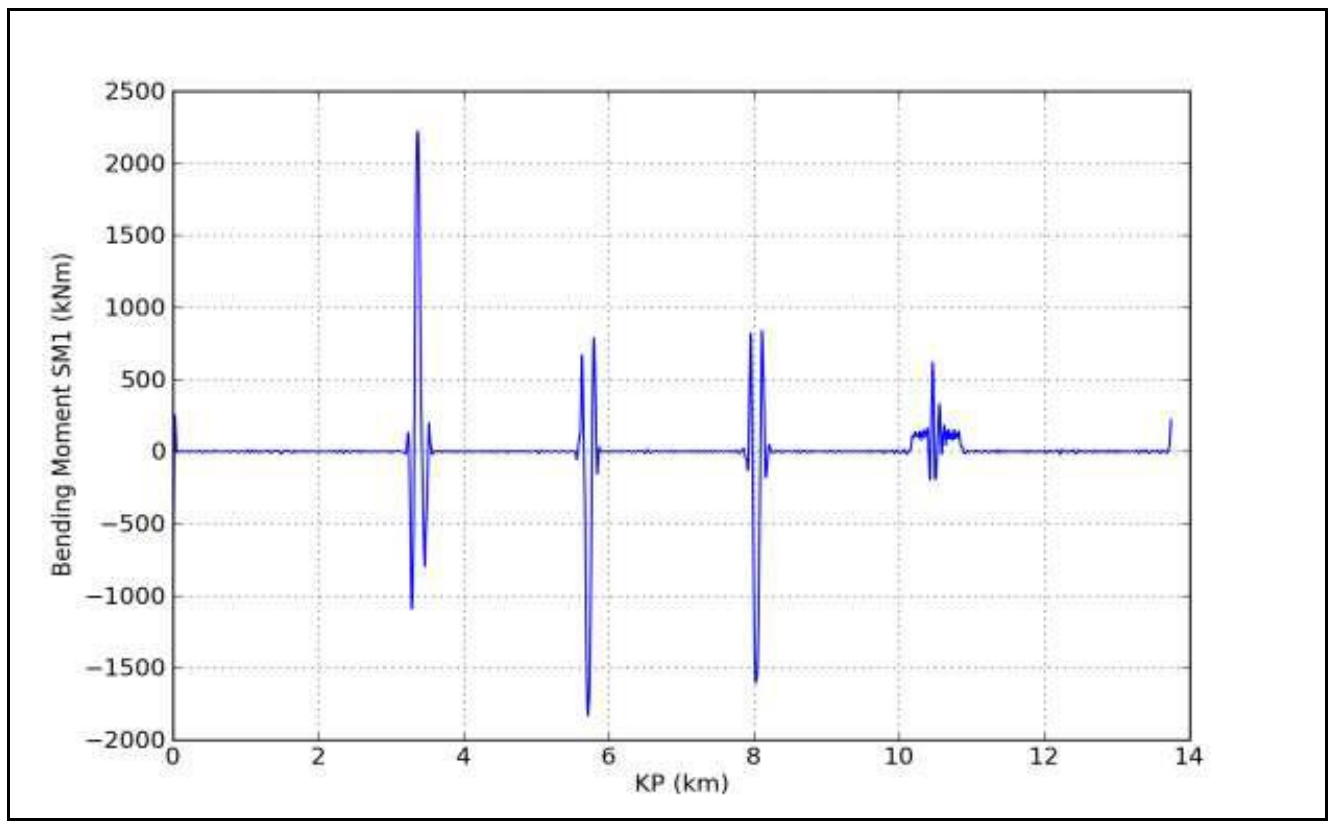

Fig. 19. Axial mechanical strain along the pipeline length 
Table 1. Load controlled local buckling check

\begin{tabular}{|c|c|c|c|c|c|}
\hline Case & Location (KP) & $\begin{array}{c}\text { Maximum } \\
\text { Moment }(\mathrm{kN} . \mathrm{m})\end{array}$ & $\begin{array}{c}\text { Maximum Axial } \\
\text { Force }(\mathrm{kN})\end{array}$ & $\begin{array}{c}\text { Utilisation } \\
\text { Factor }\end{array}$ & Results \\
\hline \multirow{3}{*}{ (a) Base } & 3.386 & 2229.76 & -502.71 & $\mathbf{0 . 7 9 5}$ & OK \\
\cline { 2 - 6 } & 5.762 & 1875.69 & -485.76 & 0.593 & OK \\
\cline { 2 - 6 } & 8.091 & 1747.93 & -472.83 & 0.529 & OK \\
\hline
\end{tabular}

Table 2. Displacement Controlled Local Buckling Check

\begin{tabular}{|c|c|c|c|c|c|c|c|c|}
\hline \multirow{2}{*}{ Case } & \multirow{2}{*}{$\begin{array}{c}\text { Max. } \\
\text { Mechanical } \\
\text { Compressiv } \\
\text { e Strain }(\%)\end{array}$} & \multirow{2}{*}{ SCF } & \multicolumn{3}{|c|}{ SNCF } & \multirow{2}{*}{$\begin{array}{l}\varepsilon d \cdot S \\
N C F \\
(\%)\end{array}$} & \multirow{2}{*}{$\begin{array}{l}\text { Utilisat } \\
\text { ion } \\
\text { Factor }^{(3} \\
\quad \text { ) }\end{array}$} & \multirow{2}{*}{$\begin{array}{c}\text { Resul } \\
\text { ts }\end{array}$} \\
\hline & & & $\begin{array}{c}\text { Weak } \\
\text { Joint }^{(1)}\end{array}$ & $\begin{array}{l}\text { Field } \\
\text { Joint }\end{array}$ & $\begin{array}{c}\text { Combine } \\
\mathrm{d}^{(2)}\end{array}$ & & & \\
\hline (a) & 0.142 & 1 & 1 & 1 & 1 & 0.142 & 0.340 & $\mathrm{OK}$ \\
\hline (b) & 0.14 & 1 & 1 & 1 & 1 & 0.14 & 0.337 & $\mathrm{OK}$ \\
\hline (c) & 0.143 & 1 & 1 & 1 & 1 & 0.143 & 0.341 & OK \\
\hline (d) & 0.156 & 1 & 1 & 1 & 1 & 0.156 & 0.358 & OK \\
\hline (e) & 0.136 & 1 & 1 & 1 & 1 & 0.136 & 0.332 & $\mathrm{OK}$ \\
\hline
\end{tabular}

The finite element analysis results given in Fig. 17, 18 and 19 show that the post buckling axial force in Fig. 17 are well above the Hobbs critical buckling line while the maximum axial compressive strain has reduced to lower than $0.15 \%$ which is way below that maximum limit of $0.51 \%$. The solution meets all design criteria but the pipeline installation cost is higher for strain based design due to stringent welding criteria leading lower installation rate, the buckle trigger installation and the time required to form Zero Radius Bend.

\section{Detailed design: The solution}

During this stage all the pipeline elements had been thoroughly screened for optimization where conservatism made in FEED were mitigated by performing detailed analysis. This include the assessment of FEED proposed CWC thickness of $40 \mathrm{~mm}$ against $5 \mathrm{~mm}$ required CWC thickness for the thicker-wall pipe section $(28.58 \mathrm{~mm}$ WT). The proposed $40 \mathrm{~mm}$ concrete coating thickness was on the basis of practical concrete coating application and effective anode design based on 0.8 utilization factor whereby the anode would be thinner than the anode re-enforcement bar and detached from the pipeline before the end of design life. Prior to detailed design, alternative design approach was initiated:

1) To assess if concrete coating would still be required if directional environmental load is used in the stability analysis for the thicker pipe section.

2) To re-calculate pipeline temperature profile considering no concrete coating on the pipeline.

3) To perform quick check if the pipeline would still be susceptible to lateral buckling.

The results were encouraging. Concrete coating is not required for the thicker pipeline section after considering directional wave data and lateral buckling is most likely would be avoided when the pipeline does have concrete coating. 


\subsection{Detailed lateral buckling screening}

The pipeline detailed design proceeded considering no concrete coating on the thicker pipeline section from KP0 to KP4.6 using temperature profile shown in Fig. 20 below. The section length increase by $0.6 \mathrm{~km}$ to include the pipe length which was purchased for the buckle trigger locations.

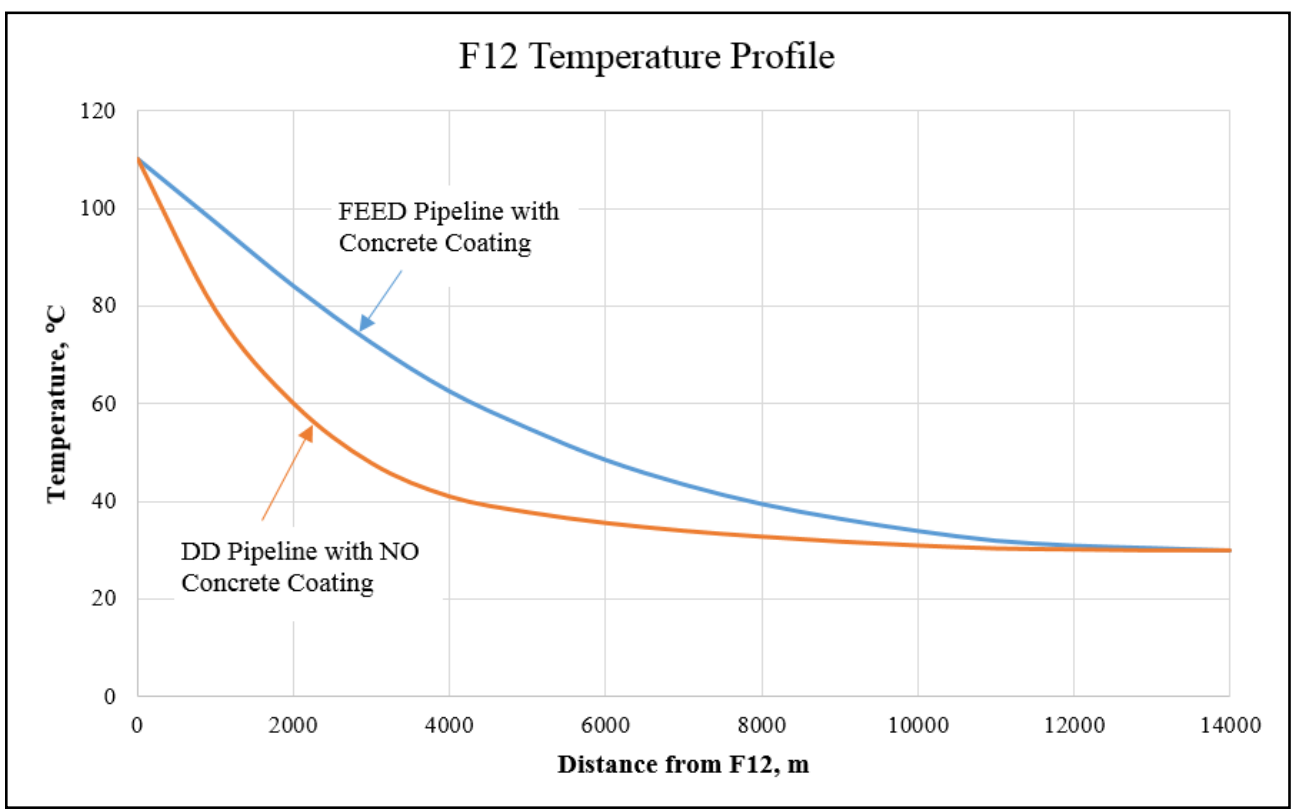

Fig. 20. Pipeline temperature profile with \& without concrete coating

Although, the effective axial force from the analytical screening for the design temperature combined with design pressure case still cross Hobbs critical buckling lines, the graph move above (See Fig. $21 \& 22$ ) when maximum operating pressure is used (combined with design temperature).

Since the design pressure is a hypothetical case to cater for failure of pipeline safe guarding system, it is unlikely that full pressurization will coincide with the design temperature. Hence the result in Fig. 22 is a good indication that lateral buckling is no longer a risk for the pipeline. 


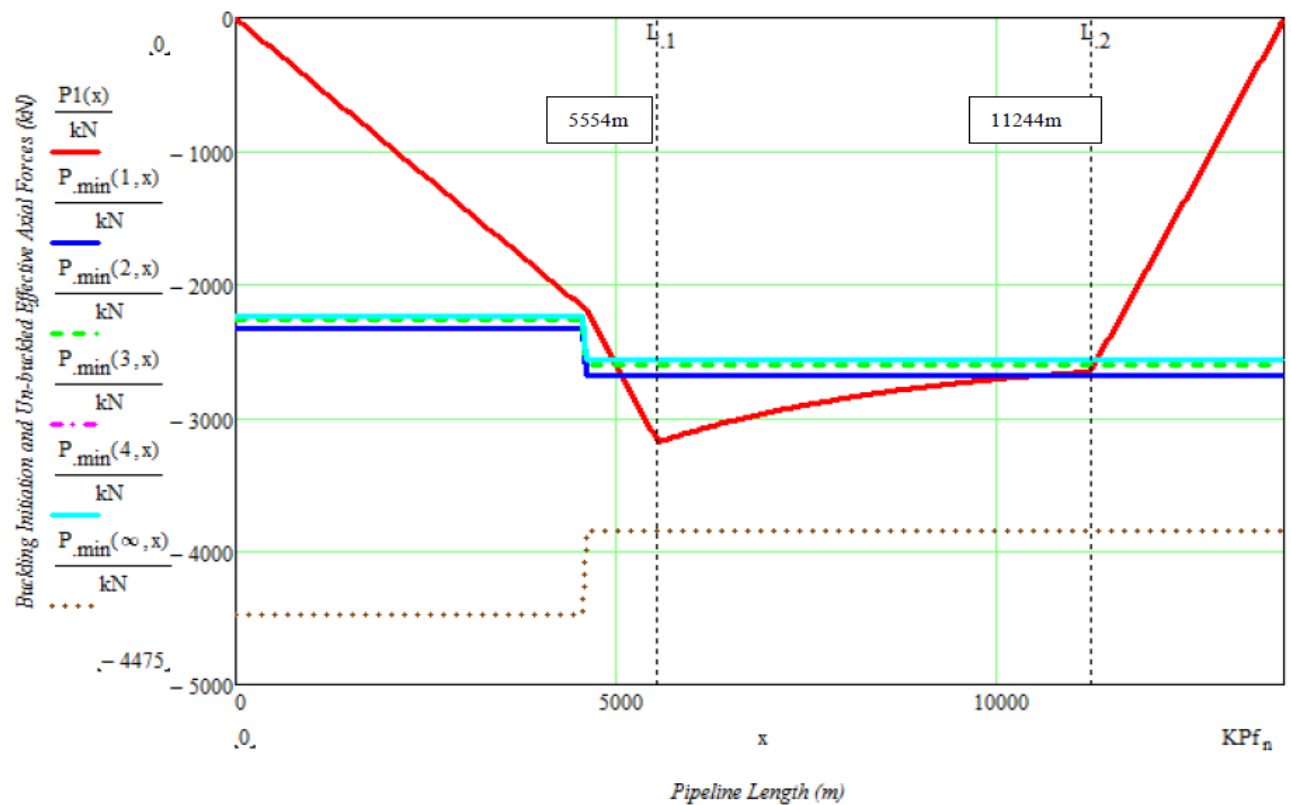

Fig. 21. Unmitigated effective axial force based on design temperature and design pressure with no concrete coating on the pipeline

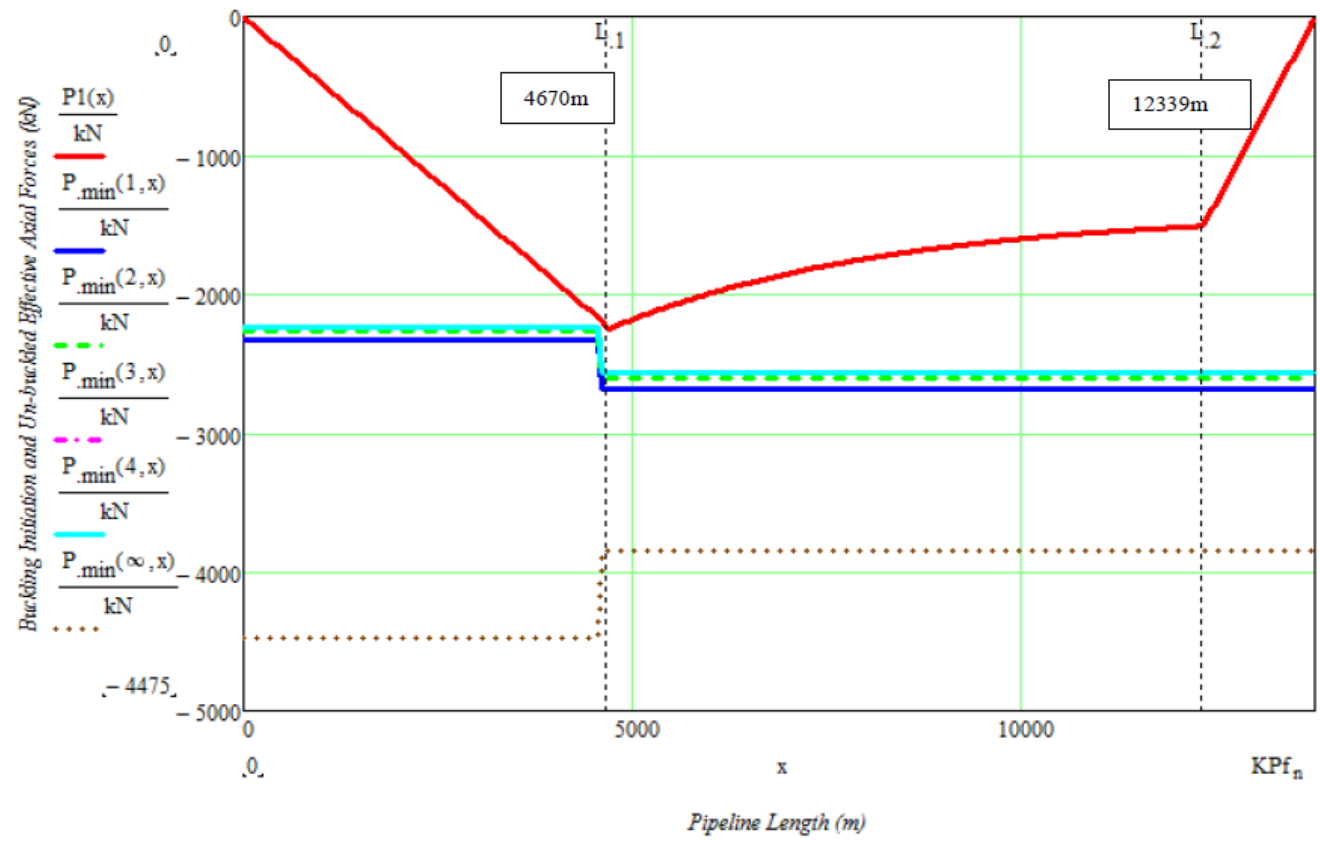

Fig. 22. Unmitigated effective axial force based on design temperature and maximum operating pressure with no concrete coating on the pipeline

The three dimensional finite element analysis was repeated to evaluate the reduction in effective axial force based as installed condition on the natural seabed terrain with no concrete coating on the first $4.6 \mathrm{~km}$ and the resulting pipeline temperature profile. Pipeline design temperature and design pressure were considered in the analysis to represent the 
worst scenario. The analysis was carried out with mean value of both axial and lateral friction factors.

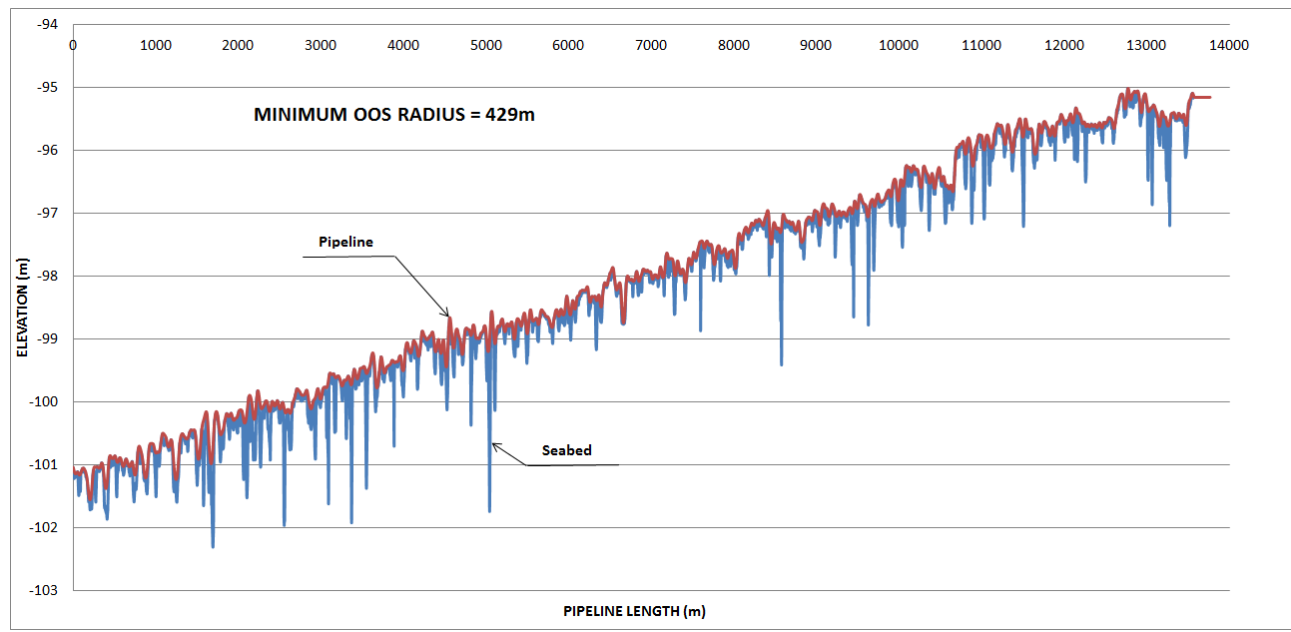

Fig. 23. Natural pipeline deformation profile on the seabed based on design operational condition

From the assessment of the natural pipeline deformation profile on the seabed under the design temperature and design pressure condition, the minimum vertical radius of curvature is estimated to be $429 \mathrm{~m}$ occurring at KP 5.070. This minimum curvature has been verified against out-of-straightness susceptibility to lateral buckling using Hobbs method as recommended in DnV RP F110 and confirmed not susceptible. See Table 3 below.

Table 3. Minimum Curvature Susceptibility Check

\begin{tabular}{|c|c|c|c|c|}
\hline $\begin{array}{c}\text { Axial } \\
\text { Friction/ } \\
\text { Lateral } \\
\text { Friction }\end{array}$ & $f_{L}^{L B}$ & $\begin{array}{c}\text { Minimum Radius } \\
\text { of Curvature due } \\
\text { to Seabed Profile } \\
(\mathbf{m})\end{array}$ & $\begin{array}{c}\text { Corresponding } \\
\text { Critical Effective } \\
\text { Axial Force (kN) }\end{array}$ & $\begin{array}{c}\text { Lateral } \\
\text { Buckling } \\
\text { Susceptibility }\end{array}$ \\
\hline UB/LB & 1337 & 429 & 574 & NO \\
\hline
\end{tabular}

To further qualify that the lateral buckling risk has been eliminated, the detailed design finite element analysis incorporate initial lateral imperfections at the location where the line is expected to experience maximum effective axial force. The line was then loaded up with design temperature and pressure allowing it to expand into the simulated imperfection. Table 4 presents the results for various imperfection combinations. Typically $0.5-2 \mathrm{~m}$ lateral installation imperfection are normally considered for the assessment to account $\mathrm{S}$ Lay out-of-straightness. The strains were factored with strain concentration factor (SNCF) of 1.263 while the bending moments were factored with concrete coating stiffness factor (CSF) of 1.12 to account for concrete coating stiffness. These value are reported as adjusted stain and bending moment in Table 4.

As seen from Case 1 to Case 5 results in Table 4, the maximum strain in the pipeline is only $0.20 \%$ after considering the SNCF as compared with $-0.582 \%$ (Fig. 12) estimated during FEED without applying any imperfection and SNCF. From Cases 6 it can be seen the strain is only $0.23 \%$ if installation out-of- straightness goes up to $2 \mathrm{~m}$. The displacement control check and load control check are all within the limit. Hence buckle mitigation measure is not necessary. 
Table 4. Maximum Effective Axial Force and Bending Moment along the Pipeline Route

\begin{tabular}{|c|c|c|c|c|c|c|c|c|c|c|c|c|c|c|c|}
\hline \multirow[b]{2}{*}{$\begin{array}{l}\tilde{E} \\
\hat{\sigma}\end{array}$} & \multicolumn{2}{|c|}{ Friction } & \multirow[b]{2}{*}{ 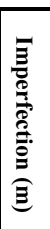 } & \multirow[b]{2}{*}{ 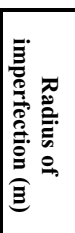 } & \multicolumn{8}{|c|}{ Operating load case } & \multicolumn{2}{|c|}{$\begin{array}{c}\text { Utilisation } \\
\text { Factor }\end{array}$} & \multirow[b]{2}{*}{ Results } \\
\hline & tut. & 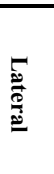 & & & 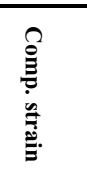 & 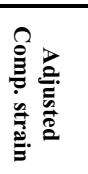 & 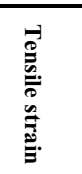 & 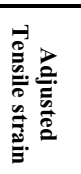 & 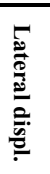 & 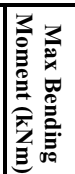 & 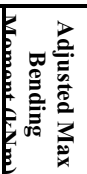 & 氞 & 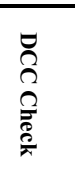 & $\begin{array}{l}5 \\
\hat{2} \\
0 \\
\frac{0}{0} \\
\frac{2}{\pi}\end{array}$ & \\
\hline 1 & $\mathrm{BE}$ & $\mathrm{BE}$ & 1 & 966 & $-0.15 \%$ & $-0.19 \%$ & $0.14 \%$ & $0.18 \%$ & 1.8 & 1214 & 1365 & 1303 & 0.607 & 0.77 & $\mathrm{OK}$ \\
\hline 2 & $\mathrm{BE}$ & UB & 1 & 794 & $-0.11 \%$ & $-0.14 \%$ & $0.08 \%$ & $0.10 \%$ & 0.3 & 772 & 868 & 2155 & 0.457 & 0.513 & $\begin{array}{c}\text { NO } \\
\text { BUCKLING }\end{array}$ \\
\hline 3 & $\mathrm{BE}$ & LB & 1 & 1202 & $-0.16 \%$ & $-0.20 \%$ & $0.16 \%$ & $0.20 \%$ & 2.2 & 1317 & 1480 & 1193 & 0.625 & 0.867 & OK \\
\hline 4 & UB & $\mathrm{BE}$ & 1 & 936 & $-0.15 \%$ & $-0.19 \%$ & $0.15 \%$ & $0.19 \%$ & 1.9 & 1250 & 1405 & 1267 & 0.607 & 0.804 & OK \\
\hline 5 & LB & $\mathrm{BE}$ & 1 & 993 & $-0.10 \%$ & $-0.13 \%$ & $0.07 \%$ & $0.09 \%$ & 0.2 & 610 & 686 & 1537 & 0.493 & 0.34 & $\begin{array}{c}\text { NO } \\
\text { BUCKLING }\end{array}$ \\
\hline 6 & $\mathrm{BE}$ & $\mathrm{BE}$ & 2 & 764 & $-0.18 \%$ & $-0.23 \%$ & $0.17 \%$ & $0.21 \%$ & 2 & 1357 & 1525 & 1189 & 0.678 & 0.91 & $\mathrm{OK}$ \\
\hline
\end{tabular}

\subsection{Consequence of eliminating concrete coating}

However, allowing pipeline temperature to cool down faster by eliminating concrete coating could lead to water condensation of on the pipe wall especially at the top of the pipeline inside diameter. This concern was confirmed by internal corrosion study. The top of line corrosion increase significantly at un-coated flange and field joint coating location, if the U-value of the coating material is around $25 \mathrm{~W} / \mathrm{m}^{2} . \mathrm{K}$ that is commonly used in for offshore pipeline. It was then calculated that minimum $\mathrm{U}$-value of $70 \mathrm{~W} / \mathrm{m}^{2} . \mathrm{K}$ is required for the field joint coating so that the top of line corrosion will remain within the design corrosion allowance of $7 \mathrm{~mm}$ for the thicker pipe section. As presented in the Fig. 24 below the top of line corrosion at the field joint has become less than the section coated with 3 layer polypropylene coating. The graph show high corrosion rate at the flange when it is not coated. The corrosion model was then incorporated with a U-value of flange thermal insulation cover (see Fig. 26). The result in Fig. 25 show significant reduction of top of line corrosion. This leads to the decision to install the thermal insulation on the flange.

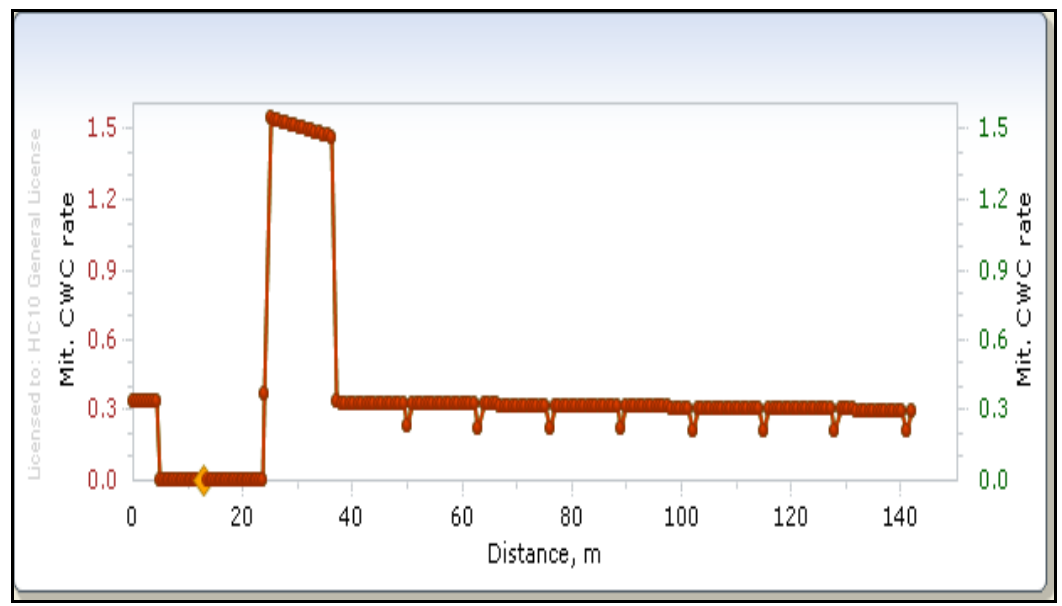

Fig. 24. Top of Line Corrosion Rate with Un-insulated Flange 


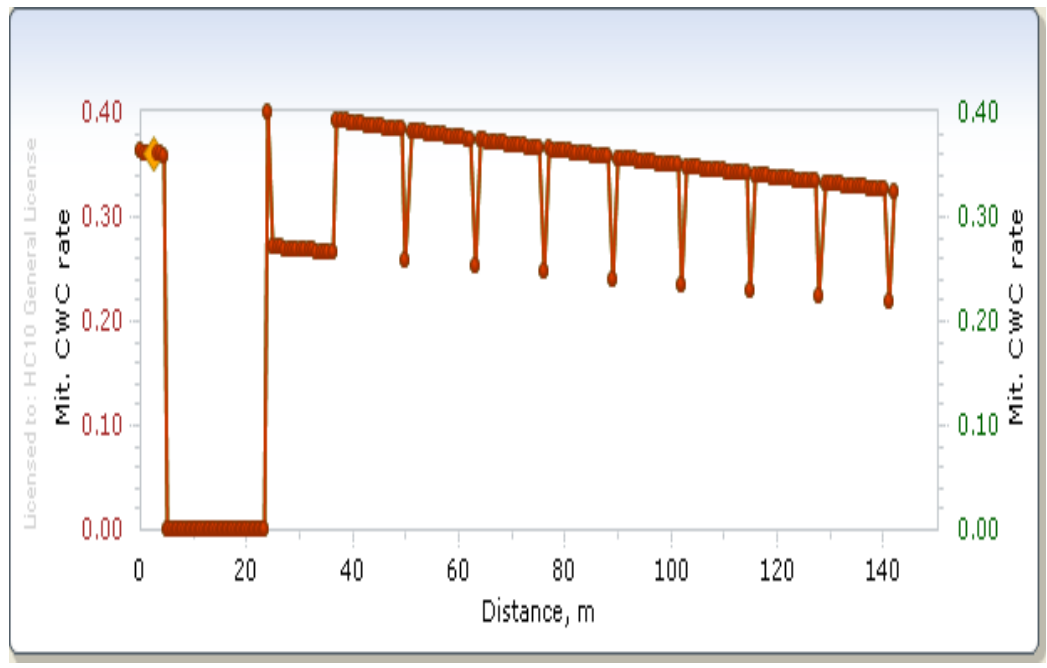

Fig. 25. Top of Line Corrosion Rate with Insulated Flange

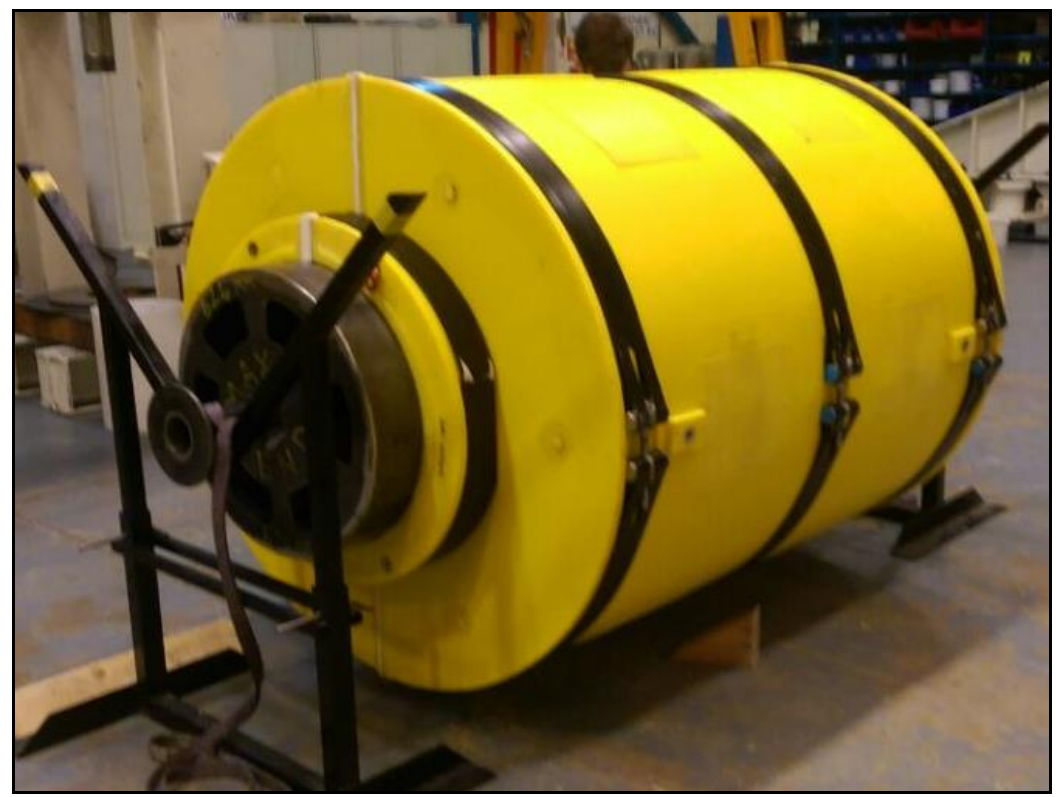

Fig. 26. Flange Thermal Insulation Cover

Now that the pipeline do not have concrete coating, the common design approach to have bracelet anode flushed with the concrete coating thickness for the cathodic protection is not possible anymore. Bracelet anode with tapered ends was proposed but due to past experience the installation team did not have much confidence with the capability of local contractors to install un-concrete coated pipeline and keeping the tapered anode remain intact. The option of using anode sled to provide cathodic protection for the hot end area was studied. It was found that:

1) The anode sled design ensures that the anode material will not be exposed to the pipeline temperature. Hence it eliminates the issue that the anode can be exposed to high temperature exceeding $80^{\circ} \mathrm{C}$ (See ISO 15589-2) for Galvalum III anode. 
2) With the lower anode temperature, the anode performance is high and leads to lower total anode weight.

3) Only one sled with 7 number of $1139 \mathrm{~kg}$ slender stand-off anodes installed at KP 2.38 is adequate to protect the pipeline.

With only minimal additional installation cost, it is incomparable to the total cost saving offered the overall design approach. This option was then selected.

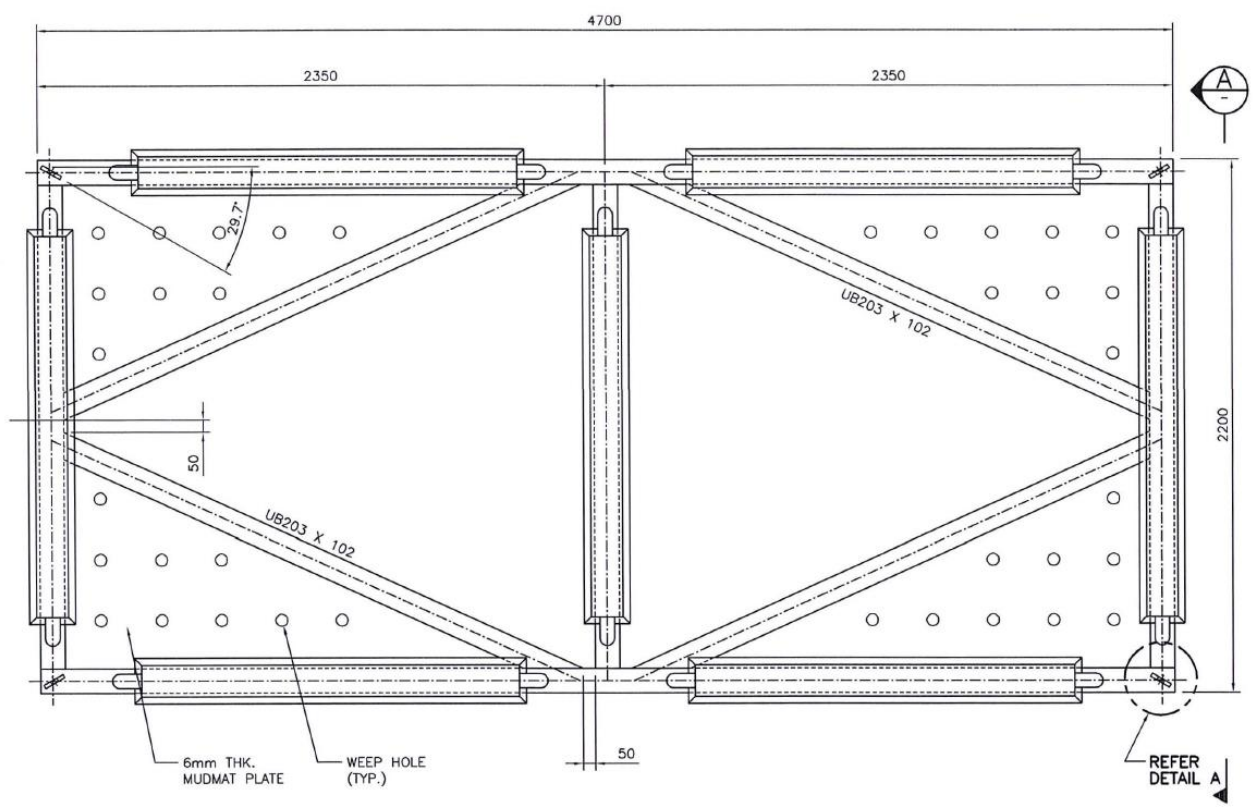

Fig. 27. Anode Sled General Arrangement

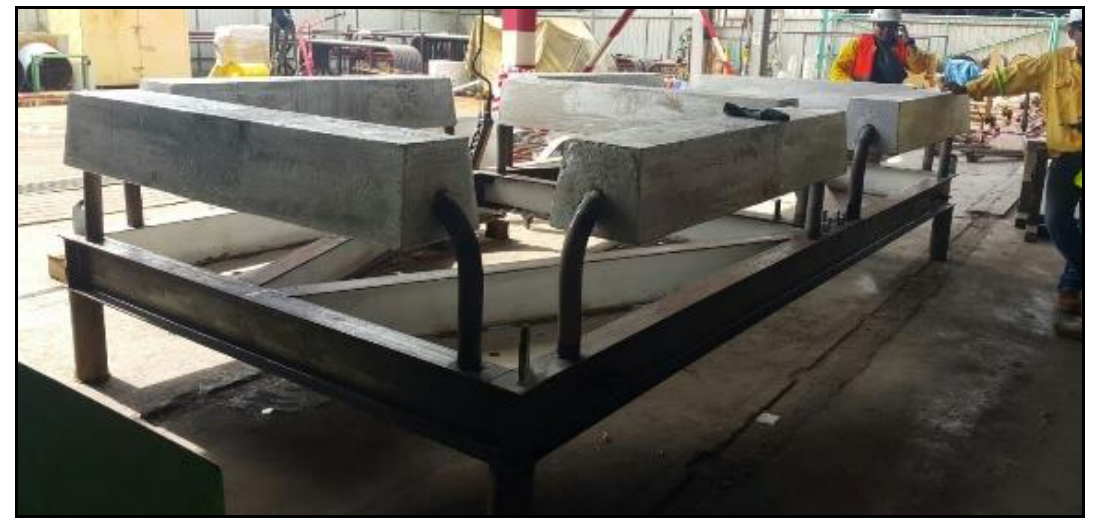

Fig. 28. Anode Sled Picture 


\section{Conclusions}

Finally, through the diligent engineering exercise the project cost for pipeline scope was reduced by approximately $4 \%$. It can be learned that holistic design approach in designing HPHT Pipeline had offered significant cost saving towards Project CAPEX as well as its Life Cycle Cost. Designing HTHP pipeline requires comprehensive all round assessment in every detailed information, change of parameters, design consideration and construction method. The interaction and involvement of related disciplines such as geotechnical, process, material and corrosion is very important. Also, the detailed soil information was an important parameters for the design.

In conclusion the experiences, lessons learnt and good practices from this project include:

1) Obtaining detail soil information is necessary for designing HTHP pipelines to arrive with optimised solution

2) For HTHP pipeline design detailed temperature profile shall be produced for each proposed wall thickness, corrosion coating and concrete coating combinations considering thermal conductivity properties of the materials.

3) Lowering temperature profile will help to optimize lateral buckling design however the effect on internal corrosion shall be analysed especially for FWS pipeline with potential top of line corrosion due to water condensation.

4) It is important to ensure that the selected field joint coating system for the HTHP pipeline will give equal or better $U$-value with the adjacent pipe joints.

5) It is recommended to assess the effect on top of line corrosion if un-concrete-coated section is used for the buckle apex area of concrete coated pipeline as this can be a risk.

6) The internal corrosion study shall model accurately any bare section at the hot end area to evaluate the top of line corrosion rate due to condensation.

7) The effect of pipeline temperature on anode performance can be eliminated by utilizing anode sled for the high temperature area especially where the pipeline temperature is above $80^{\circ} \mathrm{C}$.

8) For HTHP pipeline the decision to opt for pre-installed riser against stalk-on method shall consider the requirement of flange insulation.

\section{References}

1. DNV (RP F110), Global Buckling of Submarine Pipelines, Structural Design Due to High Temperature/High Pressure

2. DNV (OS F101), Submarine Pipeline Systems, 